\title{
From Diversity to Inclusion
}

\author{
Marie Dillon Dahleh, $\mathrm{PhD}$, \\ Tulane University, USA, mdahleh@tulane.edu
}

\begin{abstract}
Tulane is currently ranked \#2 nationally in percentage of undergraduate degrees in engineering awarded to women-tied with MIT. There is still work to be done to improve the diversity of the student population with respect to ethnicity. This paper provides a snapshot of the current diversity along with a diversity plan and support programs at Tulane aimed at supporting a diverse student population. One important strategy is to create an environment in the school of science and engineering which is focused on Inclusion. Keyword-diversity, inclusion, faculty learning community
\end{abstract}

\section{INTRODUCTION}

Tulane University traces its roots back to 1834 when it was founded as the Medical College of Louisiana. Today Tulane consists of 9 academic schools serving 8740 undergraduate students and 5459 graduate and professional students. These include Architecture, Business, Liberal Arts, Professional Advancement, Public Health and Tropical Medicine, Science and Engineering, Law, Medicine and Social Work. The first six schools offer programs at both the undergraduate and graduate level. The remaining three only have graduate education. For the fall of 2019, Tulane has 654 tenor or tenor track faculty and 1280 non tenure track faculty. A discussion of the diversity of the undergraduate student body of Tulane provides context for the later discussion of the diversity of the School of Science and Engineering (SSE) and ultimately the engineering programs.

For the last three years the undergraduate population has been rough $60 \%$ women and $40 \%$ men. Table 1 provides information on the ethnic background for the three underrepresented populations in Science and Engineering, American Indian, African American, and Hispanic. The overall percentage of student who identify as American Indian, African American, and Hispanic has remained relatively flat. Over the three- year period there has been a slight decrease in students who identify as African American, $7.83 \%$ in 2017 compared with $7.02 \%$ in 2019 and a slight increase in students who identify as Hispanic, $7.44 \%$ compared with $8.18 \%$.

Table 1: Percentage of Tulane Undergraduates who identify with the Ethnic group

\begin{tabular}{|l|l|l|l|}
\hline Ethnic & 2017 & 2018 & 2019 \\
\hline $\begin{array}{l}\text { American } \\
\text { Indian }\end{array}$ & 0.23 & 0.21 & 0.21 \\
\hline $\begin{array}{l}\text { African } \\
\text { American }\end{array}$ & 7.83 & 7.21 & 7.02 \\
\hline Hispanic & 7.44 & 7.99 & 8.18 \\
\hline
\end{tabular}

Digital Object Identifier (DOI):

http://dx.doi.org/10.18687/LACCEI2020.1.1.350

ISBN: 978-958-52071-4-1 ISSN: 2414-6390
The School of Science and Engineering offers 16 undergraduate majors, three of which are engineering. The demographics for SSE do not mirror the demographics of Tulane as a whole. For the same time period, 2017-2019, the percentage of students in SSE who are women has increased. In $2017,66 \%$ of the undergraduates in SSE were women. It increased to $68 \%$ in 2018 and held steady at $68 \%$ for 2019 . Table 2 provides information on the underrepresented ethnic background of SSE students for this time period. One should note that the percentage of students who identify as African American in SSE is lower than for all Tulane undergraduates and with the exception of 2018 the percentage of students who identify as Hispanic is also lower in SSE than the total undergraduate population.

Table 2: Percentage of SSE Undergraduates who identify with the Ethnic group

\begin{tabular}{|l|l|l|l|}
\hline Ethnic & 2017 & 2018 & 2019 \\
\hline $\begin{array}{l}\text { American } \\
\text { Indian }\end{array}$ & 0.26 & 0.30 & 0.33 \\
\hline $\begin{array}{l}\text { African } \\
\text { American }\end{array}$ & 4.30 & 4.14 & 4.93 \\
\hline Hispanic & 6.71 & 8.04 & 7.44 \\
\hline
\end{tabular}

\section{A. Engineering Demographics}

As mentioned previously, the school of science and engineering offers three undergraduate majors in engineering; Biomedical Engineering, Chemical Engineering and Engineering Physics. It offers both the Master's degree and the Ph.D. in Biomedical Engineering, Chemical and Biomolecular Engineering and Material Science and Engineering. Table 3 Provides data for the school as a whole.

18th LACCEI International Multi-Conference for Engineering, Education, and Technology: "Engineering, Integration, and Alliances for a Sustainable Development" "Hemispheric Cooperation for Competitiveness and Prosperity on a Knowledge-Based Economy", July 27-31, 2020, Virtual Edition. 
Table 3: Data for the Engineering programs and affiliated faculty

\begin{tabular}{|l|l|l|l|}
\hline Data Category & Fall 2017 & Fall 2018 & Fall 2019 \\
\hline T/TT faculty & 24 & 23 & 24 \\
\hline NTT faculty & 11 & 13 & 15 \\
\hline UG enrolment & 400 & 379 & 338 \\
\hline $\begin{array}{l}\text { UG degree } \\
\text { Conferred }\end{array}$ & 62 & 89 & 67 \\
\hline $\begin{array}{l}\text { UG student 6-year } \\
\text { graduation rate }\end{array}$ & $83 \%$ & $83 \%$ & $85 \%$ \\
\hline $\begin{array}{l}\text { Master's student } \\
\text { enrolment }\end{array}$ & 14 & 14 & 27 \\
\hline $\begin{array}{l}\text { Master's Degrees } \\
\text { Conferred }\end{array}$ & 13 & 10 & 10 \\
\hline $\begin{array}{l}\text { Doctoral student } \\
\text { enrolment }\end{array}$ & 76 & 79 & 68 \\
\hline $\begin{array}{l}\text { Doctoral Degrees } \\
\text { Conferred }\end{array}$ & 3 & 11 & 11 \\
\hline
\end{tabular}

Overall the participation of women decreases as you go from undergraduate to $\mathrm{PhD}$ student to non-tenure track to tenure track faculty. Table 4 provide the data for the engineering programs with regard to women. The percentage of women undergraduates is $45 \%, 48 \%$ and $49 \%$ respectively for 2017 , 2018 and 2019. It should be noted that in the most recent Engineering by the Numbers2 which looks at the academic year 2017-2018, Tulane University is tied for second in percent of bachelor's degrees awarded to women. The percent of women in the $\mathrm{PhD}$ program is $39 \%, 38 \%$ and $41 \%$ for 2017, 2018, 2019 respectively. There is a slight decrease again in percent women in the non-tenure track $18 \%, 31 \%$ and $33 \%$. Finally, the tenured and tenure track has $21 \%, 22 \%$ and $17 \%$ for the years considered.

The percent of engineering student in the underrepresented ethnic groups is provided in Table 5. Comparing Tables 2 and 5 , one can see that the percentage of American Indian students is the same in engineering and SSE as a whole. The percentage of African American students is slightly higher in engineering than SSE in total and the percentage of Hispanic students is lower. Comparing tables 1 and 5, one can see that the percentage of both African American Students and Hispanic students is lower in Engineering than at Tulane as a whole. The percentage of American Indian students is roughly the same.

1 Graduation rates are for the University as a whole. Tulane does not track the rate for individual schools. This data is for Cohort years 2010, 2011, and 2012.
Table 4: Engineering -Female all races

\begin{tabular}{|l|l|l|l|}
\hline Data Category & Fall 2017 & Fall 2018 & Fall 2019 \\
\hline T/TT faculty & 5 & 5 & 4 \\
\hline NTT faculty & 2 & 4 & 5 \\
\hline UG enrolment & 180 & 182 & 166 \\
\hline $\begin{array}{l}\text { UG degree } \\
\text { Conferred }\end{array}$ & 28 & 40 & 32 \\
\hline $\begin{array}{l}\text { Master's student } \\
\text { enrolment }\end{array}$ & 3 & 8 & 15 \\
\hline $\begin{array}{l}\text { Master's Degrees } \\
\text { Conferred }\end{array}$ & 5 & 0 & 5 \\
\hline $\begin{array}{l}\text { Doctoral student } \\
\text { enrolment }\end{array}$ & 30 & 30 & 28 \\
\hline $\begin{array}{l}\text { Doctoral Degrees } \\
\text { Conferred }\end{array}$ & 0 & 5 & 3 \\
\hline
\end{tabular}

Table 5: Percent of engineering students in each ethnic group

\begin{tabular}{|l|l|l|l|}
\hline Ethnic & 2017 & 2018 & 2019 \\
\hline $\begin{array}{l}\text { American } \\
\text { Indian }\end{array}$ & 0.5 & 0.26 & 0.29 \\
\hline $\begin{array}{l}\text { African } \\
\text { American }\end{array}$ & 6.00 & 5.80 & 5.60 \\
\hline Hispanic & 5.25 & 7.12 & 6.80 \\
\hline
\end{tabular}

\section{B. Institutional Leadership on Diversity}

In 2013 Scott Cowin, the president of Tulane University at the time, convened a commission on Race and Tulane Values. The commission consisted of faculty, staff, students, and other stakeholders such as Board members. The commission produced a strategic plan for 2013-2023. The institution's commitment to diversity, equity and inclusion is evident through the variety of resources available on campus. The office of institutional equity, the office for academic equity, The Carolyn Barber Pierre Center for intercultural life (which houses the office of multicultural affairs and the office of gender and sexual diversity), the Newcomb Institute are each charged with supporting a diverse, equitable and inclusive campus. To strengthen this area further, the institution is currently searching for an Associate Provost for Diversity and Faculty Development/Chief Diversity Officer. At the School level, Dean Foster is committed to increasing SSE diversity, equity and inclusion

2 https://ira.asee.org/wp-content/uploads/2019/07/2018Engineering-by-Numbers-Engineering-Statistics-UPDATED15-July-2019.pdf accessed 11/25/19 


\section{Diversity Plan for the School of Science and Engineering}

Priority 1) Increase the diversity of the students and faculty in engineering.

This priority will be achieved through five goals. The first is related to increasing the diversity of students who apply, are admitted and ultimately matriculate to Tulane.

Goal 1) Increase the diversity of students admitted and matriculated to Tulane who are interested in engineering.

A strong partner with SSE on this goal is the Office of Undergraduate Admissions (OUA) which operates within the basic philosophy that it must be a leader in college access in the local community in order to earn credibility recruiting nationally and employs a three-part approach to increasing diversity among Tulane's incoming first-year students: early outreach, recruitment, and yield activities. Programmatic outreach efforts begin with a Bridge Program for local Eighth Grade students. New Orleans middle-school students spend the day on Tulane's campus learning how to start thinking about college at the beginning of their high school careers. The OUA reaches out to high school students through longstanding formal collaborations with the community-based organizations POSSE and College Track. The OUA visits every Orleans, Jefferson, East Baton Rouge, and St. Tammany Parish high school annually, hosts a Campus Preview Day for Louisiana residents, develops Louisiana-specific recruitment materials, attends fairs hosted by the Louisiana Association of Collegiate Registrars and Admissions Officers, and hosts luncheons for guidance counselors in the region. The OUA strengthens the overall diversity of its applicant pool through extensive local recruitment.

In the fall the OUA hosts PreviewTU, a multicultural flyin program for prospective students interested in applying to Tulane. Prior to 2017, this program included approximately eight prospective students. In 2018, the OUA funded travel for more than 162 prospective students to visit campus during PreviewTU. While on campus, these students attend workshop applications, attend a fall open house, and meet current Tulane undergraduates. Applicants selected to participate in PreviewTU possess academic qualifications that makes it likely they will succeed at Tulane if admitted.

The OUA hosts a second fly-in program in the spring,
BienvenueTU, focused on first-generation college and Pelleligible, low-income admitted students. In 2019, 160 admitted high school seniors participated in Bienvenue TU. Of these students, 131 interviewed for an additional scholarship; the 29 participants who did not interview for additional scholarships were POSSE and College Track students. The OUA has hired Diversity Fellows, current Tulane students who contribute to student body diversity, to serve as mentors to both the prospective students at PreviewTU and admitted students at BienvenueTU. The flyin programs have proven effective in increasing yield: The yield rate for participants in these programs is 10 points higher than yield for the overall admitted student population.

The OUA supplements the Bienvenue TU with additional yield initiatives. The OUA hosts online multicultural themed chats for admitted students that include representation from OUA, including the Diversity Fellows, and campus partners. Diversity Fellows and admission counselors call admitted students, and the OUA holds multiple online chats throughout the year for prospective or admitted students to talk to admission counselors, student life representatives, and current Tulane students. The OUA has conducted phone call and text campaigns to engage with admitted students across the United States, as well. The OUA partners with the office of Academic Equity and The Carol Barber Pierce Center for Intercultural Life for programing during the Fly- Ins. These offices provide both academic and social emotional support for students at Tulane.

A new SSE initiative which will be launched this year in partnership with OUA, is a Tulane Innovation and Research award for select admitted students to entice them to attend Tulane and to major in an SSE major. The award will provide a guaranteed paid REU to be used during the freshmen year. By engaging students early in the SSE community, it is hoped that they will be retained. The diversity of award recipients will be considered as part of the process.

The Tulane Center for k-12 STEM Education is housed in SSE. The center runs programs for students in grades k-12 and for teacher professional development. In the summer the center runs the Tulane Science Scholars Program (TSSP) for high school students. This program awards college credit to students. The program is both residential and day. Since 2013, when TSSP began offering for-credit courses, over 400 students have participated in the program. Among TSSP participants who graduated high school between 2014 and 2017 (171 students), 21 have enrolled at Tulane University and 76 percent are STEM majors. The TSSP program brings a 
diverse set of students to campus. For example, in the summer of 2019, 149 students participated (from 26 different states and 1 U.S. Territory (Puerto Rico) as well as 4 international students from 3 different countries (China, Spain, Turkey)). In this cohort $31 \%$ of the students identified as underrepresented minority and $58 \%$ female.

Goal 2) Create and maintain pathways to attract underrepresented populations.

In addition to the TSSP as a pathway, Tulane has a 3-2 program with Xavier University, an HBCU in New Orleans. Currently this program has 5-8 students participating in it. The participation in the program has varied over the years. The advisors in engineering are committed to working with Xavier and Tulane to increase the participation of Xavier students. This effort will include information sessions at Xavier in the fall as well as detailed advising information for Xavier students about how to complete both degrees in the 5year time frame. SSE has funding for 3 full tuition waivers per year for Xavier students. Once the pathway from Xavier is solidified, SSE will work with Dillard University, another HBCU in New Orleans to create a pathway for their students.

Goal 3) Increase the retention of diverse students in Engineering.

Last spring in an effort to draw more students into Chemical Engineering, the program created a freshmen class, Impacts in Chemical Engineering. This year a service-learning component is being added to the course. Based on the success of this course, the three engineering programs will create an intro to engineering course, designed to be taken in the fall of the freshmen year. It will introduce students to broad concepts in engineering such as design, teamwork and societal impacts. Students can follow this class by spring discipline specific courses such as the chemical engineering course.

Last year SSE joined the KEEN network in order to infuse the curriculum with the entrepreneurial mindset. Several engineering faculty have participated in KEEN events and are developing curriculum based on what they have learned. In addition to this activity, Tulane office of technology transfer sponsors a yearlong Novel Tech Challenge. SSE supports this challenge as does the Burton D. Morgan Foundation. SSE is home to the Ackerman Maker Space which is open to all students, faculty and staff who want to be makers. This space supports classes, the Novel Tech Challenge and anyone who wants to be a maker.

Foundational courses in mathematics, chemistry and physics take advantage of supplemental instruction. Supplemental instruction is an internationally recognized support program at Tulane University. It provides out of class review sessions where students can work collaborative on problems, compare notes, and complete additional practice problems. Students who participate in five or more sessions over the semester see improved performance in these classes.

Tulane has active SWE and NSBE chapters. The Physics and Engineering Physics department has a newly created Society for Women in Physics and Engineering (SWIPE) which brings together women who are undergraduates, graduates and faculty for events including mentoring. SSE is investigating adding student chapters of SACNAS and AISES. The school has faculty who are active in both of these organizations.

SSE has funds for scholarships and materials for students. One fund is designated for women and one for minority students. Moving forward SSE will ensure that these funds are used to support one student in engineering and one in science each year. The process has not previously balanced these awards.

Goal 4) Increase the recruitment diverse graduate students in engineering.

The number of underrepresented graduate students is very low. A first step in increasing the enrollment is to increase the diversity of the applicant pool. This will be achieved with a couple of activities. As part of our partnership with Xavier University and Dillard University we will hold graduate school info sessions at these schools. The school will recruit at SACNAS, NSBE and AISES. These activities are targeted at increasing the applicant pool. Faculty will undergo bias training which should help in both reviewing graduate student files and potential faculty files.

Goal 5) Increase the recruitment and retention of diverse faculty in engineering.

This year, search committees are being asked to review training materials related to increasing equity in the search process. The school will undergo bias training in the spring. One of the priorities for the New Associate Provost for Diversity and Faculty Development/Chief Diversity Officer position is to create policies and procedures to help faculty perform a more equitable search.

Priority 2) Increase the feeling of belonging in SSE Goal 1) Create an SSE committee composed of faculty, staff, graduate students and undergraduate students, whose role is to advise the executive committee of the school on issues related to inclusion in SSE including opportunities which promote inclusion.

Goal 2) Create mechanisms to evaluate teaching for effectiveness, equity and inclusion.

Goal 3) Provide Annual implicit bias training for faculty 
This priority is supported by faculty development opportunities such as the ASEE national teaching effectiveness institute and the AAU STEM network meetings. This year the AAU meeting will focus on creating inclusive classrooms in introductory STEM classes.

This year SSE is hosting a faculty learning community on inclusive excellence. The intention is to develop a definition of inclusive excellence for the school and to start to work on ways to measure an inclusive classroom. We currently define inclusive excellence as the intentional movement toward equitable representation and inclusion that values the culture, backgrounds, and unique qualities of all individuals at Tulane University. The goals of this movement are to 1) increase the opportunities for professional growth of all, particularly those who have been marginalized in the past; and 2) improve the culture and climate within Tulane, such that all individuals' backgrounds, unique qualities and culture are valued and viewed as a resource to promote development and success and strengthen the institution. The faculty group is reading Becoming a Critically Reflective Teacher by Stephen Brookfield. Through increased education, it is hoped that a new system for evaluating teaching will include a way to measure how inclusive is the instruction. Based on the success of this initiative, SSE will annually support faculty learning communities around diversity, equity and inclusion.

In the Spring of 2020, the Mathematics department at Tulane is hosting a meeting for women and minorities in Mathematics, Mathematics for All. The meeting registration is at capacity with a waitlist. It convenes undergraduate, graduate as well as women faculty. It combines research talks from minority mathematicians with sessions on increasing diversity in Mathematics.

Tulane has been selected to host the American Physical Society Women in Physics meeting in January 2021. This is a great opportunity for the institution to bring to campus undergraduate women who may consider graduate school at Tulane as well as graduate students who may consider a faculty position at Tulane. Exposing more women to what Tulane has to offer will increase both diversity and inclusion.

\section{Conclusion}

Tulane University examined deeply the data on diversity of the student and faculty population in order to assess the current landscape. The percentage of undergraduate and graduate women exceeds the national averages for these groups. There is still work to do with the ethnic minorities for the student populations. The faculty diversity both with respect to gender and ethnicity needs improvement. A key strategy for improving these numbers is to improve the culture of inclusion in the school.

\section{ACKNOWLEDGMENT}

This work could not have been done without the help of the office of institutional research at Tulane University. They provided all of the data for this paper. I would like to thank The Center for Engaged Teaching and Learning at Tulane University for funding the faculty learning community. Lastly I would like to thank my colleagues in the School of Science and Engineering and the members of the learning community for stimulating work.

\section{REFERENCES}

[1] S. D. Brookfield, Becoming a Critically Reflective Teacher, second edition, San Francisco, CA: Jossey-Bass, 2017 